\title{
An investigation on the surface finish of sculptured surface utilizing reverse engineering data of crank case cover - (CATIA V5 \& DELCAM)
}

\author{
Sundi Syahrul Azwan ${ }^{1, *}$, Jumali Muhammad Syafik ${ }^{1}$, Raffay Mohamad Razly ${ }^{2}$ and \\ R.Abdullah R. Izamshah ${ }^{2}$ \\ ${ }^{1}$ Faculty of Engineering Technology, Universiti Teknikal Malaysia Melaka, Hang Tuah Jaya, 76100 \\ Durian Tunggal, Melaka, Malaysia \\ ${ }^{2}$ Faculty of Manufacturing Engineering, Universiti Teknikal Malaysia Melaka, Hang Tuah Jaya, \\ 76100 Durian Tunggal, Melaka, Malaysia
}

\begin{abstract}
The ultimate aim of this study was to investigate the effect of surface finish for a machined part which was programmed by two popular Computer Aided Design / Computer Aided Manufacturing (CAD/CAM) software namely as Catia V5 and Delcam (Delcam for Solidworks - DFS) by using scanned data obtained from one of the Reverse Engineering methods namely Three-Dimensional (3D) scanning process. A crank case cover was chosen as the physical part to be scanned and machined because of its sculptured shape and complex geometry. In this study, simultaneous three-axis machining programs were created and machined using threeaxis Computer Numerical Control (CNC) Milling machine; DMC 635 Ecoline. Furthermore, all machining parameters are remained the same for both programs. Initially, the physical crank case cover gone through the first process called scanning process using a 3D scanner; model $700 \mathrm{CX}$ in order to capture the 3D CAD data in points cloud form. The raw scanned data then gone through editing process to obtain better surfaces using Geomagic Studio software. Moreover, the stable and edited CAD model then undergone $\mathrm{CAD} / \mathrm{CAM}$ programming process for both mentioned software respectively. On the other hand, there were seven random points chosen to be analyzed for the surface roughness analysis. The arithmetic mean value ( $\mathrm{Ra}$ ) was used as the roughness value reference using Mitutoyo Surface Tester. Ultimately, it could be concluded that Catia V5 producing better surface finish compared to Delcam software concluded from the analysis carried out as presented in this paper.
\end{abstract}

\section{Introduction}

$\mathrm{CAD} / \mathrm{CAM}$ system is commonly used in daily engineering tasks. CAM may be defined as the use of computer systems to plan, manage, and control the operations of a manufacturing

* Corresponding author: syahrul.azwan@utem.edu.my 
plant through either direct or indirect computer interface with the production resources of the plant. The geometric model generated during the CAD process forms the basis for the CAM process. Various activities in CAM may require different types of information of the CAD process [1]. As it is developed through time and widely used, it needs the best decision to choose the best software to be owned. In the process of product design and manufacture, it is becoming increasingly important as competitive pressures call for improvements in product performance and quality, and for reductions in development time scale [2].

The process of discovering the technological principles of a device, object, or a system through analysis of its structure, function and operation is known as Reverse Engineering (RE). Reverse engineering has become a viable method to create a $3 \mathrm{D}$ virtual model of an existing physical part for use in 3D CAD, CAM, CAE or other software [3]. The measured data alone, usually represented as a point cloud, lacks topological information and is therefore often processed and modelled into a more usable format such as a triangular-faced mesh, a set of NURBS surfaces, or a CAD model. A digital 3D model must be constructed using a device that can analyse a real-world object or environment to collect data on its shape and possibly its appearance for example the colour. This device is known as 3D scanner. Nowadays, many different technologies can be used to build 3D-scanning devices, but each of the technology comes with its own limitations, advantages and costs. Some of the limitations of this technology that still present are optical technologies encounter many difficulties with shiny, mirroring or transparent objects [4].

The quality of the surface plays a very important role in the performance of milling as a good-quality milled surface significantly improves fatigue strength, corrosion resistance, or creep life. Surface roughness also affects several functional attributes of parts, such as contact causing surface friction, wearing, light reflection, heat transmission, ability of distributing and holding a lubricant, coating, or resisting fatigue. Therefore, the desired finish surface is usually specified and the appropriate processes are selected to reach the required quality. The machining quality was assessed through the comparison of surface roughness, surface texture and dimensional control parameters.

\section{Methodology}

Scanning process was the first step done in this research. A crank case cover is chosen as the physical part to be scanned and machined because of its sculptured and complex shape. Besides, this research initiated to be focused on application of reverse engineering in automotive industries. The scanning process was done by using 3D scanner model $700 \mathrm{CX}$. In 3D scanning, it was very hard to obtain fine surfaces from the raw data. Typical problems normally happened in the raw scanned data such as opened, overlapped and unfinished surfaces. Hence, it is really important to perform editing process in order to resolve all the problems mentioned. The editing process or smoothing process normally involves with sewing unattached surfaces, re-closing opened surfaces and re-creating overlapping surfaces. Geomagic Studio was the software used to perform the editing process. After editing process completed, the file must be saved in igs / IGES or stp / STEP file format so that it could be read in Catia V5 and Delcam software for CAM preparation. Figure 1 show the CAD model obtained after gone through editing process once the raw scanning data received from the $3 \mathrm{D}$ scanning process. 


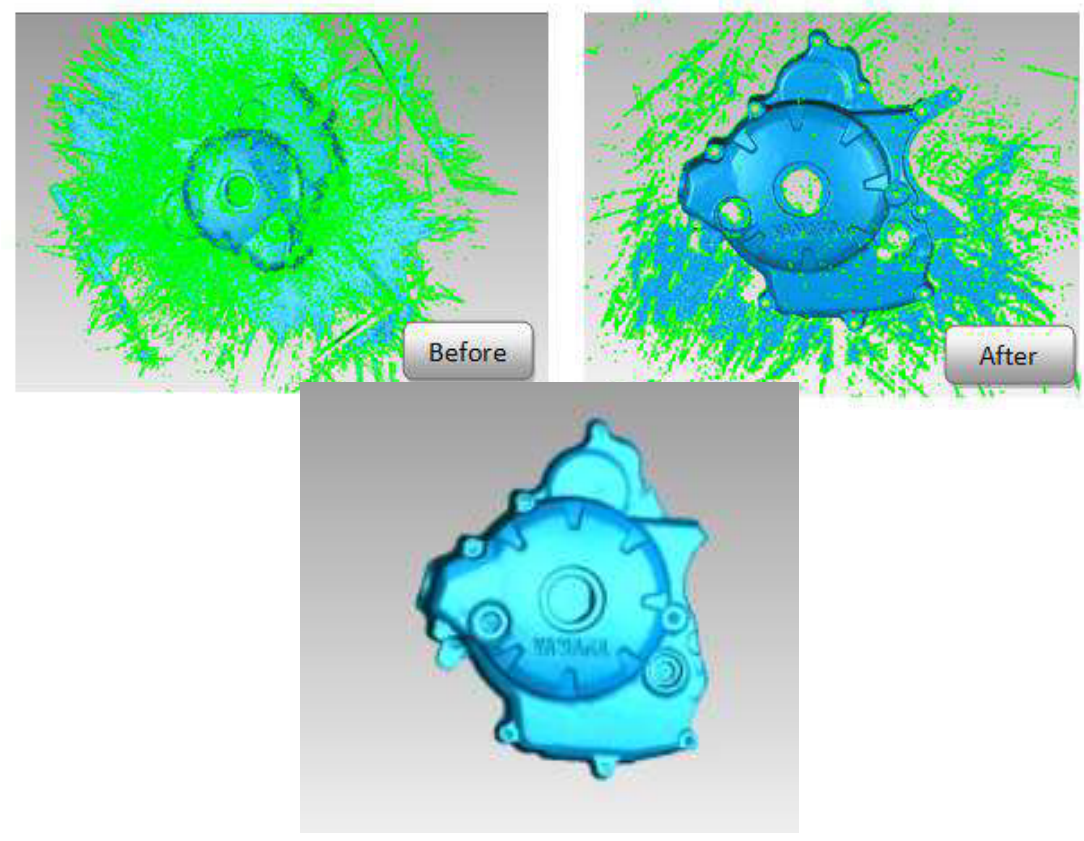

Fig. 1. The editing processes involved using Geomagic Studio.

For the physical machining, 3-Axis CNC milling machine model DMC 635 Ecoline DMG Mori machine was the machine selected. The size of raw materials or stocks prepared were $150 \mathrm{~mm}$ x $100 \mathrm{~mm}$ x $50 \mathrm{~mm}$. The material was aluminium 3000 series. Cutting tool of End Mill D16 High Speed Steel (HSS) four flutes is used to perform the roughing process. Meanwhile, Ball Nose Mill R6 (HSS) cutting tools were chosen to perform the machining on the surfaces which were to be analyzed in surface roughness analysis. In Catia V5, Advanced Machining workbench is utilized to create the CAM program. Machining process offered by Catia V5 for surface machining called "Sweeping" process. On the other hand, in Delcam software it was automatically selected by the software once the specific geometries of the 3D CAD model are defined. There were setups or settings which need to be set for both CAMs software. It is realized that some different terms used carry the same meanings such as "depth of cut" used in Catia V5 whereas "Z increment" in Delcam. Table 1 indicates the settings have been applied for both CAMs software in preparing the CAM program. Meanwhile, Figure 2 shows the completed CAM programs for both CAMs software. Completed programs were then post processed using integrated post processor and finally transferred to the $\mathrm{CNC}$ machine for physical machining.

Surface Roughness is a measurable surface characteristic quantifying high frequency deviation from an ideal surface. It is usually described by the arithmetic mean value ( $\mathrm{Ra}$ ), based on the mean of the normal deviations from a nominal surface over a specified "cut off' length and normally measured in micron meters $(\mu \mathrm{m})$. This process was done by using Mitutoyo surface roughness tester in metrology laboratory. Moreover, this analysis used a contact surface roughness tester to measure the surface finish. In other words, this method involves dragging a measurement stylus in traverse direction on the surface of the sample. The surface features were measured relatively to the drive unit reference surface. Hence, this accurately measures waviness and finally stepped features in addition to the surface roughness. 
Table 1. Settings / parameters applied for both software in preparing the CAM program.

\begin{tabular}{|c|c|c|}
\hline Softurate & Catis 15 softwart & Deinam safruate \\
\hline Process & Roughing 1 roughtimg? & Rough Z-ievel \\
\hline Spiodle sqeed & 700 ipe & 7000 трш \\
\hline Offet os part & $1 \mathrm{~mm} / 0.25 \mathrm{~mm}$ & $0.25 \mathrm{~mm}$ \\
\hline $\begin{array}{l}\text { Machining } \\
\text { tolersece }\end{array}$ & 0.1 mete & $0.1 \mathrm{man}$ \\
\hline Depth of cut & $1.5 \mathrm{~mm} / 0.25 \mathrm{~mm}$ & $0.25 \mathrm{~mm}$ \\
\hline
\end{tabular}

\begin{tabular}{|c|c|c|c|}
\hline Seffuare & Catis is softurase & Soffuare & Dekram whtwwar \\
\hline Procest & sneeping & Process & Finint Zeverel \\
\hline Spindle speed & $7000 \mathrm{~mm}$ & Spiodle operd & 7000 трш \\
\hline $\begin{array}{l}\text { Mackining } \\
\text { toleraece }\end{array}$ & $0.1 \mathrm{~mm}$ & $\begin{array}{l}\text { Machining } \\
\text { volenasef }\end{array}$ & $0.1 \mathrm{~mm}$ \\
\hline $\begin{array}{c}\text { Maximem distance } \\
\text { between pass }\end{array}$ & $0.25 \mathrm{~mm}$ & Step over & $0.25 \mathrm{man}$ \\
\hline Oftuet an part & $6 \mathrm{~mm}$ & $\begin{array}{l}\text { Finisting } \\
\text { allowaser }\end{array}$ & $0 \mathrm{~mm}$ \\
\hline Seallop height & $0,002 \mathrm{rm}$ & Ziacrement & $0.002 \mathrm{~mm}$ \\
\hline
\end{tabular}

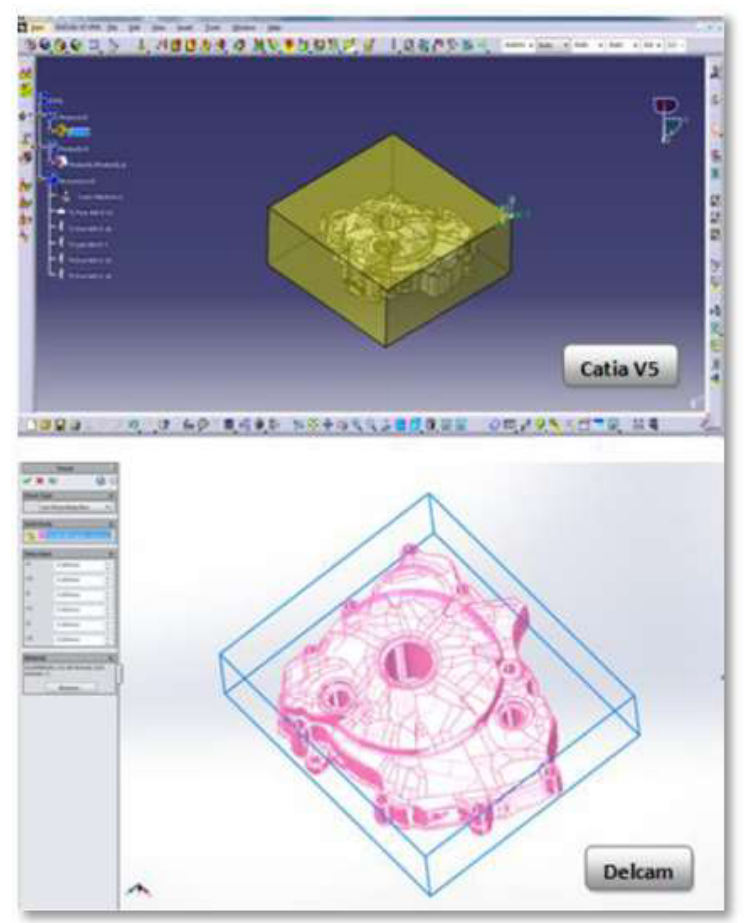

Fig. 2. Completed CAM program in Catia V5 (top) and Delcam (bottom). 


\section{Results and discussion}

In measuring the surface finish, there were seven points randomly picked on the top surface of the machined parts; crank case cover. Various locations have been chosen to be analysed. Five readings taken on every each selected point and average value then calculated. All points taken for both machined parts were approximately on the same locations. Furthermore, three readings are taken for each identified point and the average value is calculated. The stylus traverse distance was set constantly at $5 \mathrm{~mm}$ at every single reading. Figure 3 indicates the location of the points taken for the surface analysis.

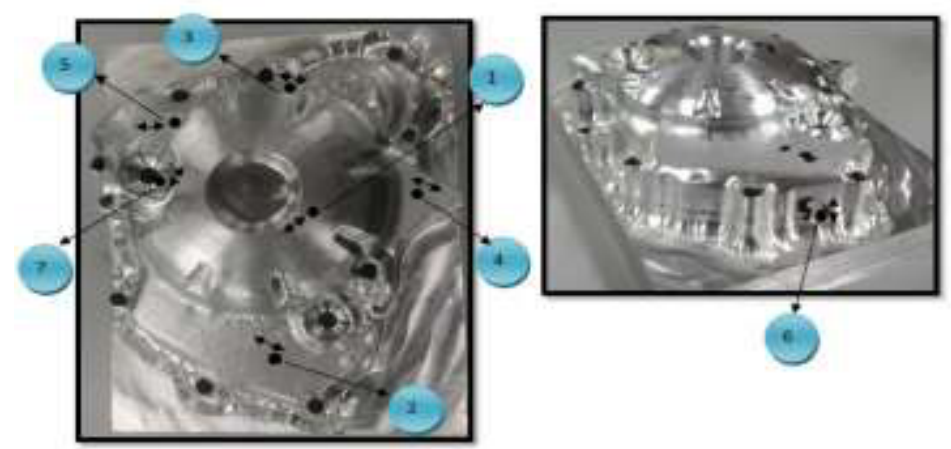

Fig. 3. Points taken in surface roughness analysis for both machined sample parts.

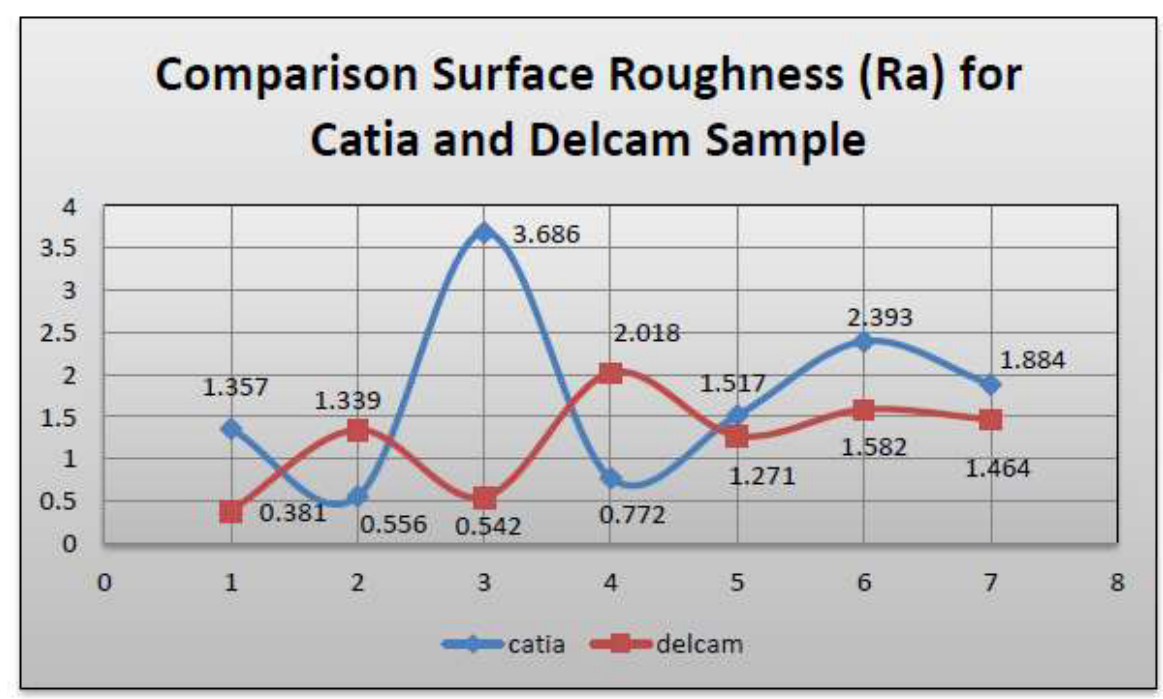

Fig. 4. Comparison of surface roughness average values for the 10 points taken.

From the result illustrates above, it is obviously shown that the highest average value for Catia V5 is $3.686 \mu \mathrm{m}$ at the $3^{\text {rd }}$ point whilst for Delcam's is $2.018 \mu \mathrm{m}$ representing the $4^{\text {th }}$ point. On the other hand, the best surface roughness value falls at the point marked as $2^{\text {nd }}$ for Catia V5 with the value of $0.556 \mu \mathrm{m}$. Meanwhile, for Delcam it falls at the $1^{\text {st }}$ point with $0.381 \mu \mathrm{m}$. This finding highlights that the same scanned 3D CAD model programmed by Delcam resulted slightly better surface finish in average than programmed by Catia V5. The main factor contributes to the result obtained was possibly caused by the different way of preparing the program. Although the same 3D CAD model were used and the same 
parameters applied, somehow the differences in determining the important settings whilst preparing the CAM program such as tool path direction and machining processes. In Catia V5 users were given options in determining the direction of tool path as this was not being offered in Delcam. In this study, the direction of the machining tool path selected was along the length of the part to be machined and in "Zigzag" motion. However, in Delcam the tool path was automatically calculated which was opposite direction from the one selected in Catia V5 and at certain areas the machining tool paths looked in "Spiral" movement. Furthermore, in Delcam there were too many shortcuts to simplify the machining program compared to Catia V5. Machining parameters were also automatically calculated from the library referring to the range set by the users as not in the practice of Catia V5. Catia V5 emphasizes details in each step and process compared to Delcam. Figure 5 shows the result of machining for both CAMs software.

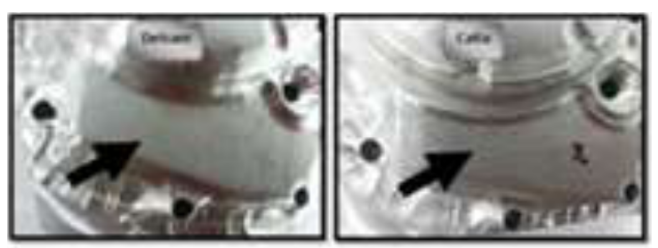

(a)
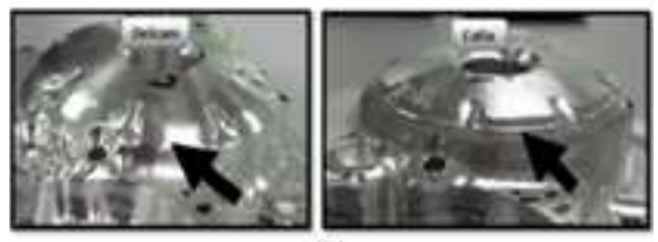

(b)

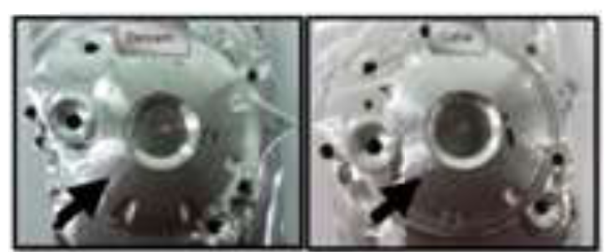

(c)
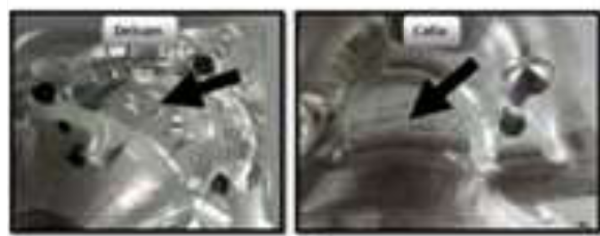

(d)

Fig. 5. Result of differences can be seen from machined sample parts - Delcam and Catia V5.

From Figure 5(a) both machined surfaces obviously indicate the differences. Surface machined by Delcam having linear lines all over the respected surface due to the effect of machining tool paths. Meanwhile, surface machined by Catia V5 has only macro lines to be compared to the Delcam's at certain specific area. This surface is marked as point 2 in the surface finish analysis. The average Ra value for Catia V5 sample is $0.556 \mu \mathrm{m}$ and $1.339 \mu \mathrm{m}$ for Delcam sample. Hence, from those two figures the surface of Catia V5 sample is definitely better than Delcam's. The main factor contributed to this result is believed due to the machining tool paths direction. In Catia V5 the direction of the machining tool path is set to along the length of the part to be machined and in "Zigzag" motion for finishing process. On the other hand, in Delcam it seems to be "Spiral" motion has been calculated for the finishing process.

Figure 5(b) illustrates the finest of profiles which were achieved by both mentioned software. Although the same machining parameters as well as the same CAM settings have been applied, the end machined results seems to be slightly different. In details, it could be seen that on certain particular areas surface machined by Delcam looks smoother than the Catia V5's. The size and type of cutting tool used for finishing process was ball end mill diameter 10mm. Again, "Spiral" direction machining tool path performed by Delcam's is believed was the main factor contributes to this result.

On the other hand, Figure 5 (c) presents the comparison of surface finish on the top area of the crank case cover. At a quick glance, both machined surfaces seems indicating approximately the same smoothness surfaces. However, the machined surface by Delcam 
obtained better result in Ra average value which stated $0.381 \mu \mathrm{m}$. Meanwhile, the average $\mathrm{Ra}$ value for Catia V5 shows greater difference approximately by almost $1 \mu \mathrm{m}$ or specifically $0.976 \mu \mathrm{m}$ more than Delcam's which is $1.357 \mu \mathrm{m}$. From the Ra value obtained, there is a significant conclusion can be drawn from this result. The differences in machining tool path direction or also called machining style / strategy really influence the result of final machined part. "Spiral" motion applied by Delcam software seems to be really effective in machining sculptured surfaces as carried out in this research. Nevertheless, "Zigzag" motion also able to give better surface finish on certain specified areas as reported.

Figure 5(d) exhibits very critical differences. The surface machined by Delcam unfortunately showed left out of unfinished materials. This is strongly believed due to the uncalculated areas determined by the automatic calculation machining tool paths method as default settings in Delcam software. On the other hand, the surface machined by Catia V5 seems to be completed and smoothly finished. Figure 6 below illustrates the machining tool paths directions for both meant software.

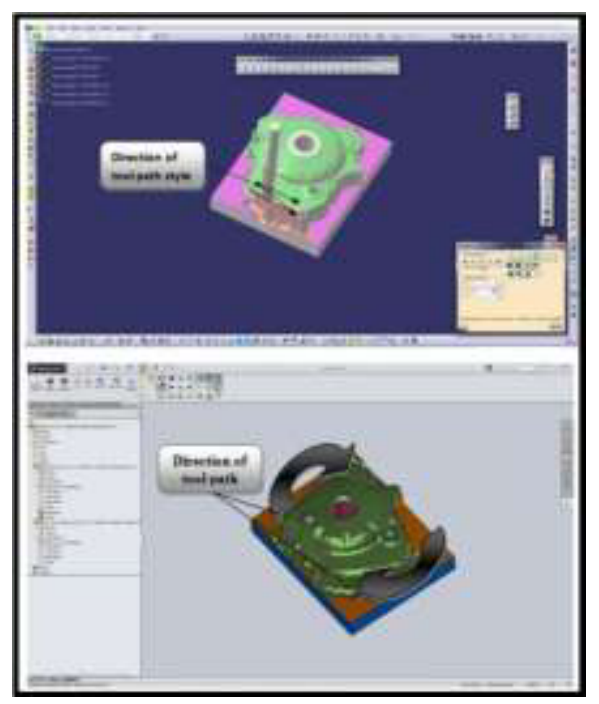

Fig. 6. Differences of tool path direction illustrated by both software.

\section{Conclusions}

In this study, the effect of surface finish of machined parts which were programmed by Catia V5 and Delcam applying one of Reverse Engineering methods namely 3D Scanned Data have been successfully investigated. The result reveals that the surface finish of machined part programmed by Delcam software is slightly better than Catia V 5 by looking at the overall average Ra values $1.22 \mu \mathrm{m}$ and $1.738 \mu \mathrm{m}$ respectively. Important conclusion drawn from this work is that; differences in preparing the CAM program especially on the machining tool paths direction as well as the details of machining processes involve also somehow effect the surface finish of the machined part although the same 3D CAD model is used as the reference.

Ultimately, Catia V5 offers higher flexibility in determining the way of CAM program to be created than the Delcam software especially the version that been used in this research; Delcam for Solidworks (DFS). Importantly, the Delcam and the Catia V5 software are able to produce the desired machined part. In particular, further research should be conducted on study of dimensional accuracy in producing machined part from 
scanned data to be compared to the actual part for both meant software.

Author acknowledges, with gratitude, authors' debt of thanks to Universiti Teknikal Malaysia Melaka (UTeM) and to the funding body; Ministry of Higher Education Malaysia for the research grant (RAGS/1/2014/TK01/UTEM/B00079).

\section{References}

1. Abbott, Steven, SPE (Surface Profile Explorer), Abbott Apps. Steven Abbott TCNF Ltd. (Retrieved January 13, 2014)

2. Baptista R. and Antune Simoes J.F., Three and Five-Axis Milling of Sculptured Surfaces, Journal of Materials Processing Technology, 103, Pages 398-403. (1999)

3. Bernardini, F., \& Rushmeier, H. E., The 3D Model Acquisition Pipeline, Compute Graphics Forum. (2002)

4. Chris McMahon and Jimmie Brownie, CAD/CAM Principle Practice and Manufacturing Management, $2^{\text {nd }}$ Edition Prentice-Hall. (1999)

5. Chennakesava R. Alavala, CAD/CAM Concept and Application, Prentice-Hall India. (2008)

6. Rozmarina Dubovska, Jaroslav Jambor and Jozef Majerik, Implementation of CAD/CAM system CATIA V5 in Simulation of CNC Machining Process, Procedia Engineering, 69, pp. 638 - 645. (2014)

7. Sundi S.A., Muhamad M.R., Bakar B.A and Abdullah, R.I.R., Surface Roughness Analysis on Five-Axis Flank Milling for Curved Shape Part-Full Flute and Ground Shank End Mill, Science International (Lahore), 26, pp. 1869-1973. (2014)

8. Sun Y.W., Guo D.M. and Jia Z.Y., Spiral Cutting Operation Strategy for Machining of Sculptured Surfaces by Conformal Map Approach, Journal of Material Processing Technology, 180, pp. 74-82. (2006)

9. Várady, T., Martin, R. R., and Cox, J., Reverse Engineering of Geometric Models Special issue: Computer-aided Design, pp. 253-254. (1997) 